\title{
Persistent ductus arteriosus: most probably a primary congenital malformation
}

\author{
ADRIANA C. GITTENBERGER-DE GROOT \\ From Department of Anatomy and Embryology, University of Leiden, Leiden, The Netherlands
}

This study was undertaken in an attempt to determint whether there is a distinct histological difference between the human normally closing ductus arteriosus and a persistent ductus arteriosus. The microscopical investigation was done in 42 specimens of human ductus arteriosus fiom subjects ranging in age from 12 hours after premature delivery to 32 years. The ducts derived from hearts avith various congenital malformations, in some of which patency of the ductus was essential for survival, as well as from hearts without other congenital malformations. Because no histological differences were found between the isolated patent ductus arteriosus and those associated with other congenital heart anomalies, the specimers were classified according to age. Stages of a normal anatomical closing process were not encountered in patients over 4 months of age with a patent duct. Younger material showed either a histologically normal stage of anatomical closure or an abnormality of the ductus wall. This abnormal histology is mainly characterised by an aberrant distribution of elastic material, the most conspicuous feature being a thick, wavy, unfragmented subendothelial elastic lamina. In respect of the question as to whether the observed histological abnormality forms part of a primary anomaly of the ductus arteriosus or is secondary to the prolonged patency, it appears that most of the evidence provides support for the view that a primary anatomical defect of the ductus wall is responsible for persistence of the ductus arteriosus.

The human ductus arteriosus has been the subject of many studies, but most of these investigations concerned normal anatomical closure (e.g. Jager and Wollenman, 1942; Danesino et al., 1955; Bakker, 1962; Hoffmann, 1964; Desligneres and Larroche, 1970) or physiological closure (e.g. Eldridge and Hultgren, 1955; Adams and Lind, 1957; Rudolph et al., 1961). Many studies have also been based on animal material (e.g. Sciacca and Condorelli, 1960; Hoefsmit, 1967; Hörnblad, 1969; Broccoli and Carinci, 1973). The monograph by Cassels (1973) entitled The Ductus Arteriosus provides an abundance of information on the human ductus arteriosus, covering a great many fields of interest and giving a good review of the literature. There is, however, sparse material published on the histology of persistent ductus arteriosus. Some comments are given by Bakker (1962), Desligneres and Larroche (1970), and Cassels et al. (1975). With respect to the pathogenesis of the persistent type, Cassels et al. (1975) think it reasonable to conclude that in some groups of heart malformations the haemodynamic oxygen tension plays a significant role in the patency of the duct, Received for publication 8 November 1976 whereas in others its persistent function as an open vessel is probably a facet of the congenital heart disease complex and related chiefly to an anomaly of the wall. The anomaly could be located at several sites in the ductus. Cassels and Moore (1973) mention that in persistent patency in man there is a deficiency of catecholamines in the duct. In addition, there might be an anomaly of the smooth muscle or oxygen receptors (Cassels et al., 1975).

The question of whether persistent ductus arteriosus might be caused by an underlying abnormality of the ductus wall became especially important after the influence of the prostaglandins and their inhibitors on the closing process of the ductus became known. These drugs might be used in infants with diseases in which either closure or patency of the ductus arteriosus could be lifesaving (Sharpe and Larsson, 1975; Sharpe et al., 1975; Friedman et al., 1976; Heymann et al., 1976; Nadas, 1976; Olley et al., 1976; Moulaert et al., 1977).

The aim of the study reported here was to determine whether there is a pronounced histological difference between the normally closing human ductus arteriosus and a persistent ductus arteriosus. 
Table Material

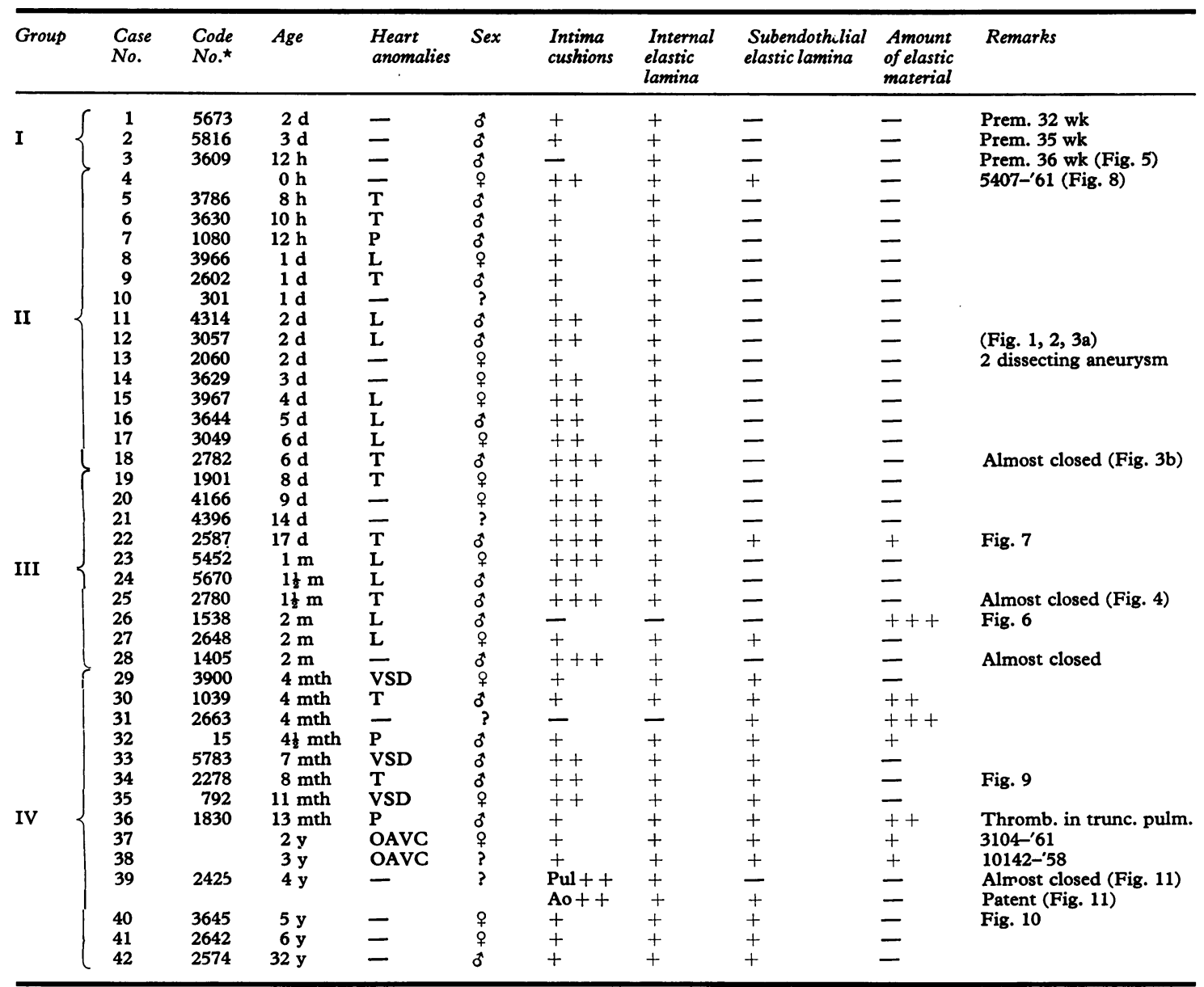

*Code No. : as in the collection of the Laboratory for Anatomy and Embryology, Leiden; T, transposition without ventricular septal defect; $P$, pulmonary atresia; L, left hypoplastic heart; VSD, ventricular septal defect; OAVC, ostium atrioventriculare commune; -, no other congenital heart anomalies.

Intima cushions: - not present (Fig. 5: 6); + not very distinct (Fig. 10); + + obvious (Fig. 1, 2, 8, 9); + + + very obvious (Fig. 7).

Internal elastic lamina: present + , absent - .

Subendothelial elastic lamina: present + , absent - .

Amount of elastic material: - normal; + slightly more fine fibres (Fig. 7 ); ++ and +++ elastic lamellae present (Fig. 6).

Cases 4, 37, and 38 were kindly put at our disposal by Dr. P. M. Bakker, Leyenburg Hospital, The Hague, and cases 1 and 2 by Dr. A. J.

M. G. Moulaert, Wilhelmina Children's Hospital, Utrecht.

The question of whether any abnormal histological picture found in the wall of a persistent ductus should be considered part of a primary defect or merely a consequence of prolonged patency is also discussed.

\section{Patients and methods}

The material consisted of 42 specimens of human ductus arteriosus from subjects ranging in age from 12 hours after premature delivery to 32 years (Table). These ducts derived from hearts with aortic atresia, pulmonary atresia, transposition without a ventricular septal defect (all anomalies in which patency of the ductus is essential for survival), ventricular septal defect, and ostium atrioventriculare commune, as well as from cases without further congenital heart anomalies. In most of the specimens post-mortem angiocardiography had been performed before anatomical and histological preparation, to show the presence or absence of anatomical patency. According to the published reports (Moss et al., 1963), in full-term infants functional closure normally takes place 10 to 15 hours after birth. Anatomical closure takes much longer, i.e. 1 week to 3 months (Cassels, 1973). On 


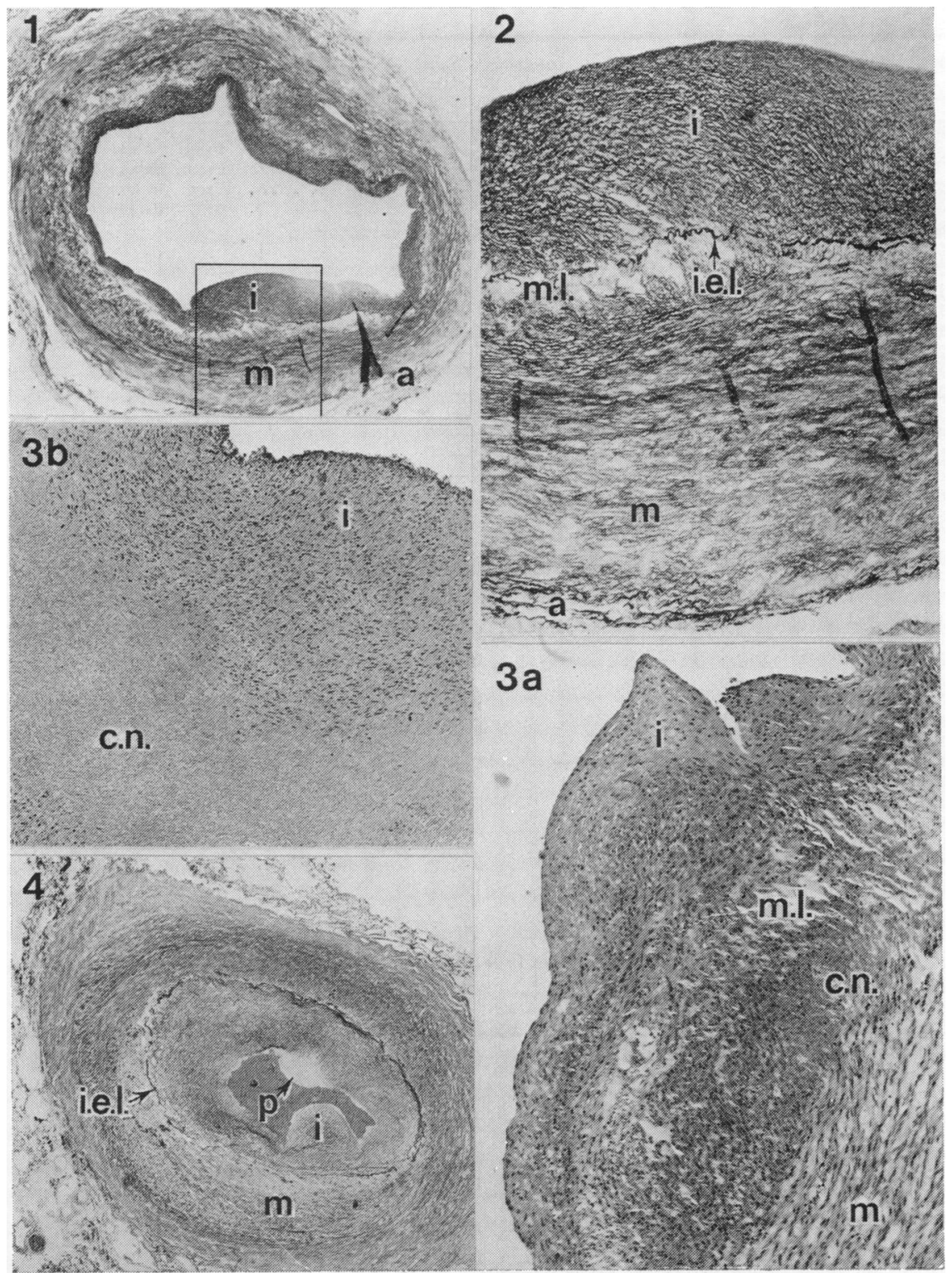

Fig. 1 Transverse section of a ductus arteriosus showing characteristics of a closing process which started normally. Case 12, aged 2 days. (Weigert elastic stain. $\times 8$.)

Fig. 2 Detail of Fig. 1. In the inner third of the media there are mucoid lakes bordering the fragmented internal elastic lamina and the intimal cushions.

$(\times 32$.

Fig. 3 (a) Detail of the wall of a ductus arteriosus. Mucoid lakes and cytolytic necrosis are present in the inner third of the media.

Same case as Fig. 1 and 2 (H. E.

$\times 32$.) (b) Detail of a wall showing a large area of cytolytic necrosis. Case 18, aged 6 days. (H. E. $\times 32$.

Fig. 4 Transverse section of an almost closed ductus arteriosus. Postnatal intimal proliferation is completely devoid of elastic material. Case 25 , aged $1 \frac{1}{2}$ months. (Weigert elastic stain. $\times 14$.)

Abbreviations used in the figures : a : adventitia; cn : cytolytic necrosis; $i$ : intima cushions; iel : internal elastic lamina ; $m$ : media; $m l:$ mucoid lakes; $p:$ postnatal intimal proliferation; sel : subendothelial elastic lamina.

the basis of these data it seems justified to conclude that persistent ductus arteriosus exists at least in all cases where the ductus arteriosus remains patent in infants older than 3 months.

All specimens were sectioned serially and studied microscopically. The plane of section was either longitudinal or transverse. In some cases the ductus was, after cleaving, sectioned in both planes. After sectioning, the material was fixed in alcohol- glycerin for staining with haematoxylin-eosin, azan, Weigert, and van Gieson elastic tissue stains, or resorcin-fuchsin-iron haematoxylin-picric acidthiazin red (standardised method of Hoefsmit, 1967).

Attention was paid to the characteristics of the normal anatomical closing process of the human ductus arteriosus, which is described by several authors, e.g. Jager and Wollenman (1942), Bakker 
(1962), Desligneres and Larroche (1970). We related our findings to the very thoroughly documented study done by Bakker (1962) on the normal closing process. The most characteristic features of the normally closing ductus (Fig. 1-4), which resembles most a muscular artery, are: (1) intimal cushions protruding into the lumen of the ductus; (2) splitting and fragmentation of the underlying internal elastic lamina (Fig. 2); (3) a media containing little elastic material; (4) a large amount of mucoid substance very often concentrated in mucoid lakes, mostly in the inner third of the media. In addition, in the later stages we see the occurrence of (5) cytolytic necrosis (Fig. $3 \mathrm{a}, \mathrm{b}$ ); and (6) postnatal intimal proliferations on top of the intimal cushions, clearly recognisable by the absence of elastic material (Fig. 4).

The amount and distribution of smooth-muscle cells and fibrous and elastic tissue was also taken into account. The elastic tissue proved to be of great importance for our study.

\section{Results}

Since no histological differences could be detected between the isolated patent ductus arteriosus and the patent ductus associated with other congenital heart malformations, the specimens were classified according to age (Table). On the basis of the findings in the reports concerning the time of anatomical closure of the ductus arteriosus, 4 age-groups were distinguished, as follows.

\section{GROUP 1}

Three ducts of prematurely born infants, with a gestational period of 32, 35, and 36 weeks, who had lived for 2 days, 3 days, and 12 hours, respectively.

The first 2 cases (cases 1 and 2) showed histologically a stage of anatomical closing process normally begun, in accordance with their age ( 2 and 3 days after delivery). The ductus of the infant who lived for 12 hours (case 3 ) did not show the abovementioned characteristics of the normal closing process in that there were no intimal cushions or mucoid lakes, and the internal elastic lamina bordered the lumen (Fig. 5).

\section{GROUP II}

Fifteen ducts, ranging in age from immediately after full-term delivery to 1 week.

Except in cases 4 and 13, the structure of the ductus wall indicated a normal closing process. In one case (case 18) the ductus was almost closed. Case 13 showed the general characteristics of a normal closing ductus but also two large dissecting aneurysms in the wall. Case 4 showed a peculiar histological anomaly which is described in the next group.

\section{GROUP III}

Ten cases, ranging in age from 8 days to 2 months. Five of these ducts (cases 19, 20, 21, 23, 24) were patent, showing stages of an anatomical closing process normally begun. Two (cases 25 and 28 ) are almost closed, showing only a very small slit-like lumen, and 3 (cases 22, 26, and 27) were patent, showing an abnormality of the wall. One specimen in the last group (case 26) showed a wall structure resembling an elastic artery rather than a muscular artery (Fig. 6). In this case the elastic lamellae of the aorta and pulmonary artery continued into the ductus wall except in a small central part of the media, whereas normally about two-thirds of the elastic lamellae merge into the adventitia of the ductus and the remaining lamellae form the internal elastic lamina (Fig. 5). In the remaining 2 cases (cases 22 and 27) and in case 4 of group II, the histological structure of the wall did not differ greatly from the picture shown by a normally closing ductus at first sight, but on closer inspection there was a remarkable feature: a conspicuous wavy unfragmented subendothelial elastic lamina (Fig. 7 and 8) over most of the intimal cushions and merging into the normal internal elastic lamina of the duct where no intimal cushions were present.

\section{GROUP IV}

Fourteen cases, ranging in age from 4 months to 32 years. All these ducts had a histologically abnormal wall. Ten (see Table) showed, as the most striking feature, the unfragmented wavy subendothelial elastic lamina (Fig. 9 and 10). In general, the intimal cushions were not very pronounced and the internal elastic lamina underneath them was often not fragmented (Fig. 10). In 7 of these cases there was no increase in the amount of elastic material in the intima or media compared with the normally closing ductus, and 3 showed a media and intima with slightly more elastic material than normal. It is not possible, however, to count the elastic lamellae as in elastic arteries. In 3 other cases, the duct showed a pronounced increase in the amount of elastic tissue with countable elastic lamellae, only the central part of the media containing slightly less elastic material. In 2 (cases 30 and 36) a few not very prominent intimal cushions were also present, and these again showed the subendothelial elastic lamina. The third case (case 31 ) bore a strong resemblance to case 26 in group III, looking more like an elastic than a muscular artery. No intimal cushions or internal elastic lamina were present, but a subendothelial elastic lamina was discernible. The 
fourteenth case (case 39) was remarkable in that the pulmonary end of the ductus was almost closed, showing all of the features of a normal closing process, whereas the aortic end was widely patent and showed the subendothelial elastic lamina (Fig. 11).

\section{Discussion}

In all cases with a patent ductus at an age of 4 months or older (group IV) the wall showed a histo- logical picture which differed from that seen during the normal closing process. In the age group from 1 week to 2 months (group III) the wall structure either reflected a normal closing process or showed an abnormality. The same holds for groups I and II.

On the basis of published data (Cassels, 1973), it seems justified from a clinical point of view to speak of persistent ductus arteriosus in all cases of patent ductus in infants older than 3 months. Since these cases always show an abnormal histo-

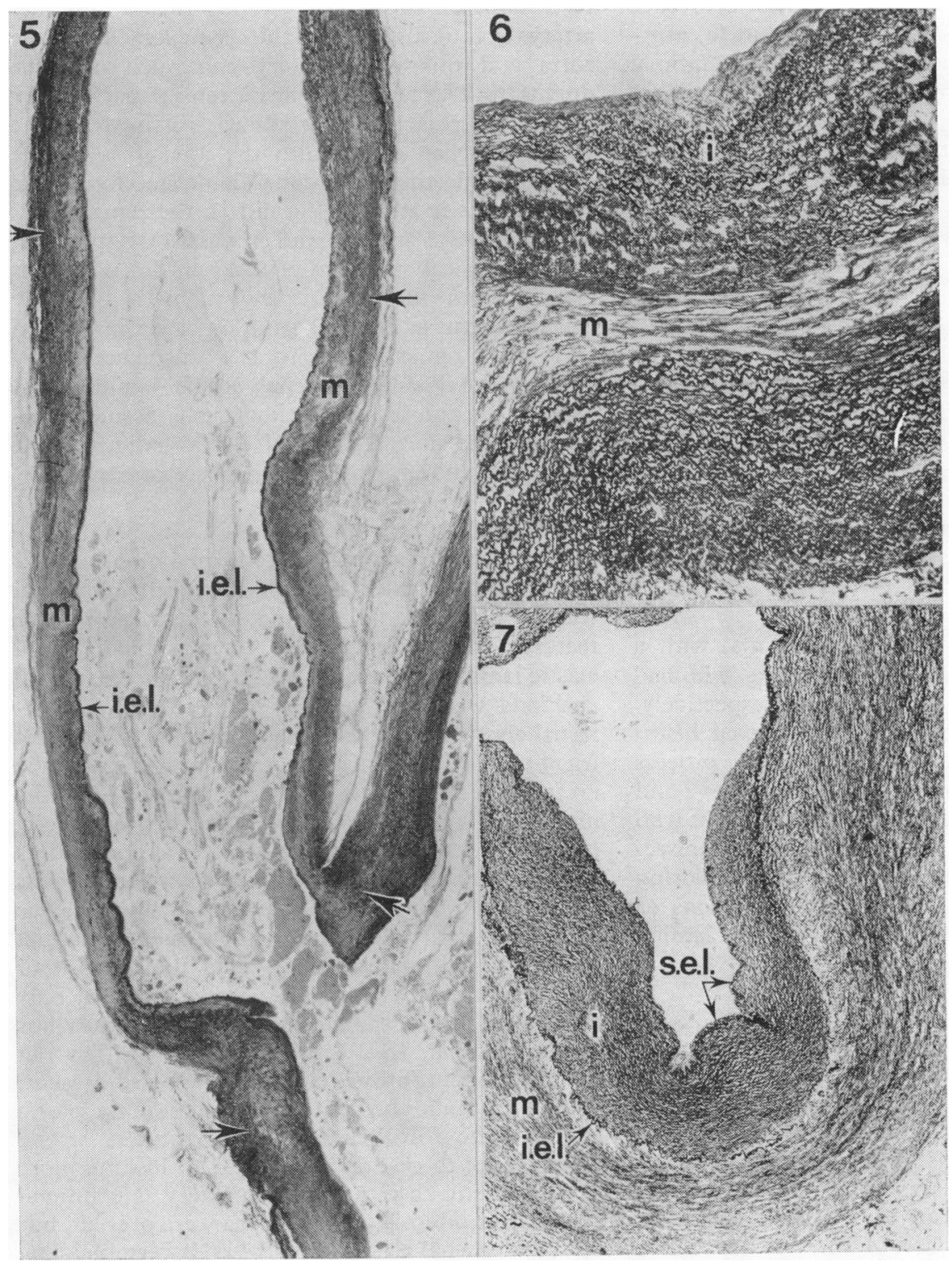

Fig. 5 Section showing ductus arteriosus and adjacent great arteries. No characteristic features of the onset of the anatomical closing process are present. The merging of the greater part of the elastic lamellae of the adjacent elastic arteries into the adventitia of the ductus arteriosus $(\rightarrow)$ is clearly visible, the remainder forming the internal elastic lamina. Case 3, prem. 36 weeks, lived 12 hours.

(Weigert elastic stain. $\times$ 13.5.)

Fig. 6 Detail of $a$ transverse section of a ductus arteriosus showing aortification. In the intima and the outer part of the media many countable elastic lamellae are present. No subendothelial elastic lamina is seen. Case 26, 2 months. (Weigert elastic stain. $\times 32$.)

Fig. 7 Transverse section of a ductus arteriosus, showing $a$ subendothelial elastic lamina on top of the intimal cushions. Intima and media contain slightly more than the normal amount of elastic material. Case 22, aged 17 days. (Weigert elastic stain. $\times 28$.) 
logy, the histologist (e.g. the present author) will be inclined to define persistent ductus arteriosus on the basis of this abnormality. The clinician, however, will encounter difficulties if he does this, because the abnormal histology is not restricted to patients older than 3 months. This raises the problem of how to differentiate clinically between persistent ductus and 'simple' prolonged patency in infants younger than 3 months. The pharmacological treatment of prolonged patency might throw some light on this problem. It is conceivable that a persistent ductus arteriosus with an abnormal histology of the wall, would not react to certain drugs, e.g. indo- methacin, which induce closure in cases of 'simple' prolonged patency. If this working hypothesis should prove to be correct, the term persistent ductus arteriosus could be used for all cases of patent ductus in patients over 3 months of age and younger infants who do not react to, for example, indomethacin. Heymann et al. (1976) mentioned that one of 15 cases of prolonged patency in premature infants did not react to indomethacin. Histological investigation of such ducts might reveal an abnormality. Further investigations are required to elucidate this problem.

The 3 premature ducts studied did not provide

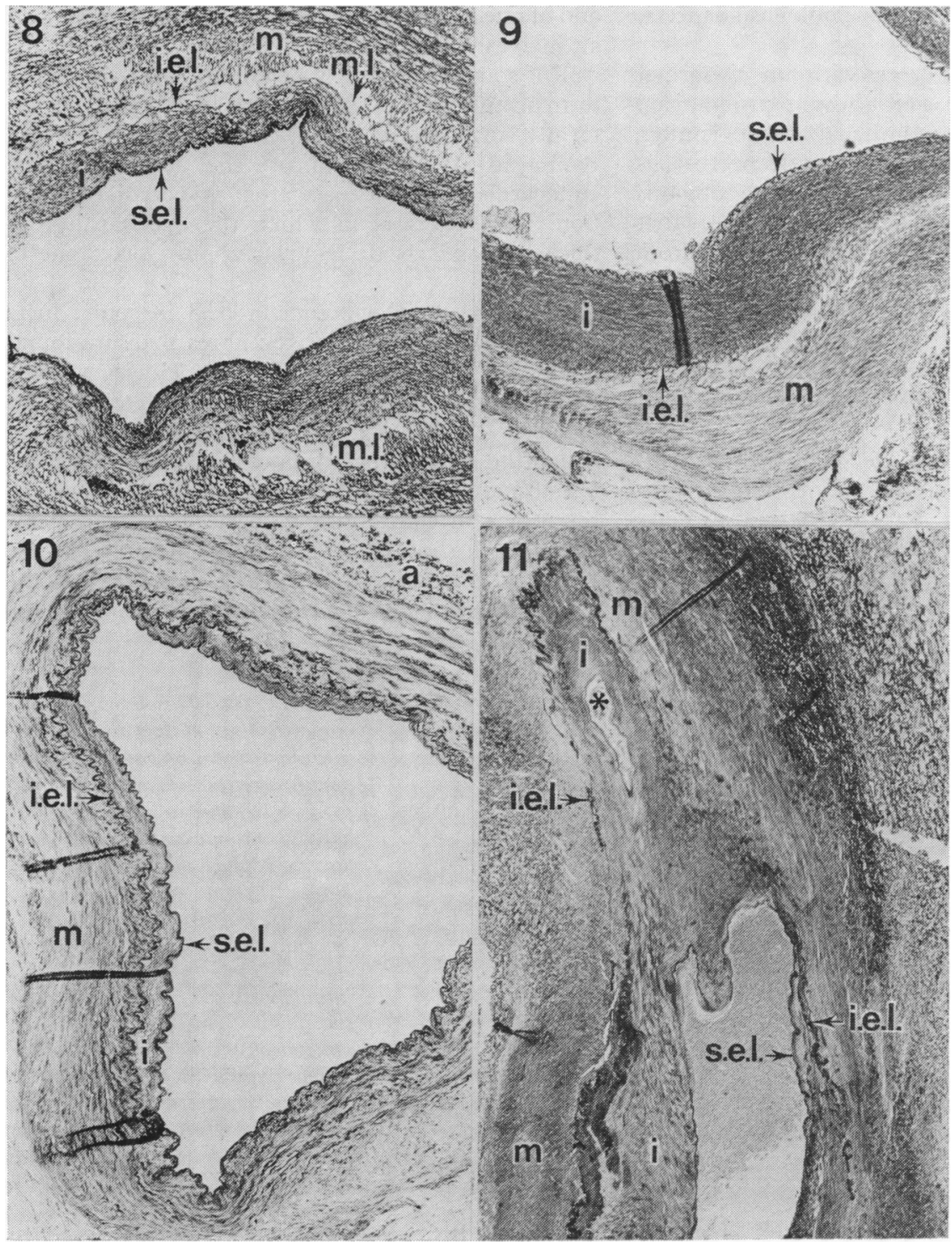

Fig. 8 Transverse section of a ductus arteriosus. The lumen is bordered by a subendothelial elastic lamina. Case 4, 0 hours. (van Gieson elastic stain $\times 28$.)

Fig. 9 Detail of $a$ transverse section of a ductus arteriosus, showing the wavy unfragmented subendothelial elastic lamina on top of an intimal cushion. Case 34, aged 8 months.

(Weigert elastic stain. $\times 28$.)

Fig. 10 Transverse section of a ductus arteriosus. The intimal cushions are not very pronounced and the internal elastic lamina is not fragmented.

Bordering the lumen, there is a subendothelial elastic lamina. Case 40, aged 5 years. (Weigert elastic stain. $\times 28$.)

Fig. 11. Section of a ductus arteriosus. The pulmonary end $\left({ }^{*}\right)$ is almost closed, whereas the aortic end is patent, showing the subendothelial elastic lamina. Case 39, aged 4 years. (Weigert elastic stain. $\times 14$.) 
enough information to draw conclusions on the often prolonged patency of the ductus of prematurely born infants. As already mentioned, two of the specimens show that the closing process had begun normally. In the third no features of anatomical closure are present, but the wall does not show any other abnormalities. Though the problem of prolonged patency of the ductus in premature infants has been discussed in many publications (Rudolph et al., 1961; Danilowicz et al., 1966; Girling and Hallidie-Smith, 1971; Benjamin and Wiegenstein, 1972; Kitterman et al., 1972; Friedman et al., 1976; Heymann et al., 1976; Nadas, 1976), I have undertaken a more detailed study with emphasis on the morphological aspects, which is now in progress.

The majority of the cases with an abnormal histology of the ductus wall show a pronounced wavy unfragmented subendothelial elastic lamina. Mucoid lakes may occur, but cytolytic necrosis is rarely encountered. There is usually no obvious increase in the amount of elastic material, so that superficially the wall does not differ greatly from that of a normally closing duct. This may account for the fact that some of the authors who studied cases with persistent ductus arteriosus state that the wall structure does not differ distinctly from that of a normally closing ductus (Wielinga, 1959; Bakker, 1962).

To the best of our knowledge, Jager and Wollenman (1942) are the only authors to mention the subendothelial elastic lamina, but they did not pay any further attention to this phenomenon. The fact that the subendothelial elastic lamina has not been described more often is in all probability explained by the lack, in the past, of histological studies in large series of persistent ductus arteriosus.

Mucoid lakes and cytolytic necrosis are also encountered during the normal closing process of the ductus arteriosus, but their significance is not known. Cytolytic necrosis is characterised by loss of nuclei (Fig. 3b); the accompanying increase of collagen fibres found by Schlatmann (1973) in aortic walls, was not seen in the present material.

Desligneres and Larroche (1970), who investigated 9 cases of patent ductus arteriosus in infancy as well as a large series of normal ducts, encountered 'more and thicker elastic fibres than usual' in the media for two cases of 'pathologic' ductus arteriosus and of one normal duct. Bakker (1962) also mentions an increase in the amount of elastic material in the wall of some specimens of patent ductus; he uses the term aortification to indicate this increase. A similar term, aorticisation, is used by Hutchins and Bannayan (1971) to indicate the development of endocardial fibroelastosis after myocardial infarction. This process, in which the endocardium is thickened and elastic lamellae appear, takes one to two years.

In our material we encountered in some ducts slightly more very fine elastic fibres than are found in normal closure (Table, Fig. 7). However, on a few occasions we saw a ductus wall with true elastic lamellae (Table; Fig. 6). For these cases, which constitute a very small minority, the term aortification can be used, indicating that the ductus wall resembles an elastic rather than a muscular artery. However, it should be stressed that we prefer to use the term only descriptively and regardless of the cause and time of development of the anomaly,
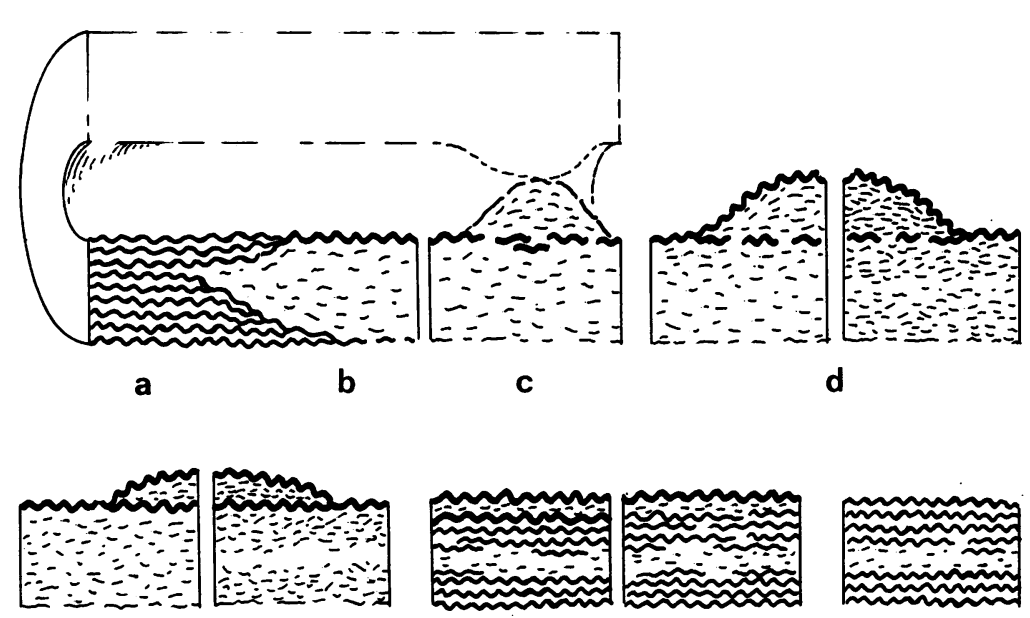

e

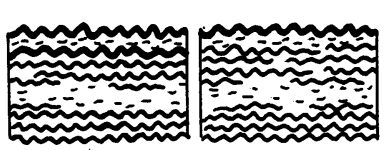

$f$

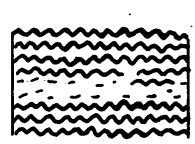

g
Fig. 12 Distribution of elastic material in an elastic artery and in various types of patent ductus arteriosus: (a) elastic artery; (b) ductus arteriosus without intimal cushions; (c) ductus showing characteristics of normally begun closing process; (d) persistent ductus arteriosus with subendothelial elastic lamina and obvious intimal cushions, in some places showing a slight increase in the amount of elastic material in the intima and media; (e) persistent ductus arteriosus as in (d), but intimal cushions not very distinct and internal elastic lamina not fragmented; $(f, g)$ persistent ductus arteriosus with aortification of the wall. 
because no relation between the duration of the patency and the amount of elastic material has been established. Fig. 12 gives a schematic representation of the distribution of elastic material in the various types of ductus wall structure.

A remarkable case is the one in which the pulmonary end of the ductus is almost closed, whereas the aortic end is patent and shows the subendothelial elastic lamina. The phenomenon of divergent behaviour of the aortic and the pulmonary ends of the ductus has been described (e.g. Bakker, 1962; Cassels, 1973). Cassels (1973: p. 311) states on the basis of his interpretation of studies done by Congdon (1922) and Keibel and Mall (1912), that this may have a developmental cause, since the ductus (6th branchial artery) originates from a ventral and a dorsal sprout; Cassels was of the opinion that 'the factors related to closure may affect the dorsal and the ventral sprout differently, allowing one or the other to remain open, the opposite segment closing normally'.

As to the question of whether the histological abnormality of the wall in persistent ductus arteriosus is secondary to the prolonged patency or part of a primary anomaly, a few points should be taken into consideration.

As indicated by the material studied (Table), there is no direct relation between age (i.e. the duration of the patency) on the one hand and the occurrence of the subendothelial elastic lamina as well as the amount of elastic material in the ductus wall, on the other hand. (The fact that we did not find many cases with an abnormal histology at a very early age will be dealt with later.) Furthermore, no relation was found between the presence of a subendothelial elastic lamina and the amount of elastic material in the intima and media. Therefore, the occurrence of a postnatal reaction of the ductus wall resembling the process described by Hutchins and Bannayan (1971), in which elastic lamellae are deposited in the endocardium over a period of one or two years after a myocardial infarction, seems improbable when cases with persistent ductus arteriosus of different ages are compared.

The altered haemodynamic situation in serious congenital heart malformations is apparently not adequate to maintain the patency of the duct. The cases with a patent ductus arteriosus associated with other congenital heart malformations are evenly distributed over the material. All too often, the ductus closes even in cases where patency would have meant survival. Another factor, e.g. a primary anomaly, must play a role. The fact that in isolated persistent ductus arteriosus, which is necessarily a primary defect, the same histological picture is found as in persistent ductus arteriosus in combination with other heart malformations, also suggests the existence of a primary abnormality.

The phenomenon that the anomaly can be restricted to one of the two sprouts from which the ductus originates (Cassels, 1973: p. 311) can be interpreted as support for the hypothesis of a primary defect of the ductus wall. Otherwise, we would have to accept that the two original components of the ductus are still differentiated, showing different reactions, a long time after the development of the ductus as a homogeneous structure.

In the present material only two young cases show the abnormal histology. One (case 4) is a neonate who died during delivery, and the other (case 22) lived 17 days. If a primary defect were involved, one would expect to find the abnormality evenly distributed over the different age-groups. However, this study was done on necropsy material, and probably there are very young infants with the anomaly who are still alive. Patients with solitary persistent ductus arteriosus do not as a rule die immediately after birth, and when it occurs in association with other congenital heart malformations it may prolong survival. Therefore, the fact that we did not find more cases showing a histologically abnormal ductus at a very early age does not necessarily mean that the difference in wall structure is a consequence of the prolonged patency.

From the above points, we can summarise as follows: (a) no relation between the duration of the patency and the amount or distribution of the elastic material, (b) altered haemodynamic situation inadequate to maintain patency, (c) the same histology in isolated persistent ductus arteriosus as when associated with other heart malformations, (d) one end of the ductus closing normally, the other end remaining patent, showing an abnormality, and (e) an abnormal histology in a neonate dying during delivery. From this we conclude that in all probability the aberrant distribution of elastic material, with the presence of a subendothelial elastic lamina as its most striking aspect, forms part of a primary anatomical defect of the ductus wall resulting in a persistent ductus arteriosus.

The author thanks Dr. P. M. Bakker and Dr. A. J. M. G. Moulaert for putting material at her disposal.

\section{References}

Adams, F. H., and Lind, J. (1957). Physiologic studies on the cardiovascular status of normal newborn infants (with special reference to the ductus arteriosus). Pediatrics, 19, 431-437. 
Bakker, P. M. (1962). Morfogenese en involutie van de ductus arteriosus. Thesis, Leiden.

Benjamin, D. R., and Wiegenstein, L. (1972). Necrosis of the ductus arteriosus in premature infants. Archives of Patho$\log y, 94,340-342$.

Broccoli, F., and Carinci, P. (1973). Histological and histochemical analysis of the obliteration processes of ductus arteriosus Botalli. Acta Anatomica, 85, 69-83.

Cassels, D. E. (1973). The Ductus Arteriosus. Thomas, Springfield, Illinois.

Cassels, D. E., and Moore, R. Y. (1973). Sympathetic innervation of the ductus arteriosus in relation to patency. Chest, 63, 727-731.

Cassels, D. E., Bharati, S., and Lev, M. (1975). Natural history of the ductus arteriosus in association with other congenital heart defects. Perspectives in Biology and Medicine, 18, 541-572.

Congdon, E. D. (1922). Transformation of the aortic-arch system during the development of the human embryo. Contributions to Embryology, No. 68.

Danesino, V. L., Reynolds, S. R. M., and Rehman, I. H. (1955). Comparative histological structure of the human ductus arteriosus according to topography, age, and degree of constriction. Anatomical Record, 121, 801-829.

Danilowicz, D., Rudolph, A. M., and Hoffman, J. I. E. (1966). Delayed closure of the ductus arteriosus in premature infants. Pediatrics, 37, 74-78.

Desligneres, S., and Larroche, J. C. (1970). Ductus arteriosus. I. Anatomical and histological study of its development during the second half of gestation and its closure after birth. II. Histological study of a few cases of patent ductus arteriosus in infancy. Biology of the Neonate, 16, 278-296.

Eldridge, F. L., and Hultgren, H. N. (1955). The physiologic closure of the ductus arteriosus in the newborn infant. fournal of Clinical Investigation, 34, 987-996.

Friedman, W. F., Hirschklau, M. J., Printz, M. P., Pitlick, P. T., and Kirkpatrick, S. E. (1976). Pharmacologic closure of patent ductus arteriosus in the premature infant. New England Fournal of Medicine, 295, 526-529.

Girling, D. J., and Hallidie-Smith, K. A. (1971). Persistent ductus arteriosus in ill and premature babies. Archives of Disease in Childhood, 46, 177-181.

Heymann, M. A., Rudolph, A. M., and Silverman, N. H. (1976). Closure of the ductus arteriosus in premature infants by inhibition of prostaglandin synthesis. New England Fournal of Medicine, 295, 530-533.

Hoefsmit, E. (1967). Het sluitingsproces van de ductus arteriosus bij de rat. Thesis, Leiden.

Hoffmann, E. (1964). Die Obliteration des Ductus arteriosus Botalli. Langenbecks Archiv für Klinische Chirurgie, 306, 289-314.

Hörnblad, P. Y. (1969). Embryological observations of the ductus arteriosus in the guinea-pig, rabbit, rat and mouse.
Studies on closure of the ductus arteriosus IV. Acta Physiologica Scandinavica, 76, 49-57.

Hutchins, G. M., and Bannayan, G. A. (1971). Development of endocardial fibroelastosis following myocardial infarction. Archives of Pathology, 91, 113-118.

Jager, B. V., and Wollenman, O. J. (1942). An anatomical study of the closure of the ductus arteriosus. American Fournal of Pathology, 18, 595-605.

Keibel, F., and Mall, F. P. (1912). Manual of Human Embryo$\log y$, Vol. 2). Lippincott, Philadelphia.

Kitterman, J. A., Edmunds, L. H., Gregory, G. A., Heymann, M. A., Tooley, W. H., and Rudolph, A. M. (1972). Patent ductus arteriosus in premature infants. Incidence, relation to pulmonary disease and management. New England Fournal of Medicine, 287, 473-477.

Moss, A. J., Emmanouilides, G. C., and Duffie, E. R. (1963). Closure of the ductus in the newborn infant. Pediatrics, 32, 25-30.

Moulaert, A., Senders, R., Ertbruggen, I. van, Huysmans, H., and Harinck, E. (1977). Effect of $E_{1}$ type prostaglandin on hypoxaemia in a cyanotic congenital cardiac malformation. European fournal of Cardiology, Vol. 5.

Nadas, A. S. (1976). Patent ductus revisited. New England Fournal of Medicine, 295, 563-564.

Olley, P. M., Coceani, F., and Bodach, E. (1976). E-type prostaglandins. A new emergency therapy for certain cyanotic congenital heart malformations. Circulation, 53, 728-731.

Rudolph, A. M., Drorbaugh, J. E., Auld, P. A. M., Rudolph, A. J., Nadas, A. S., Smith, C. A., and Hubbell, J. P. (1961). Studies on the circulation in the neonatal period: the circulation in the respiratory distress syndrome. Pediatrics, 27, 551-566.

Schlatmann, T. J. M. (1973). Het aneurysma dissecans van de aorta. Thesis, Amsterdam.

Sciacca, A., and Condorelli, M. (1960). Involution of the ductus arteriosus. Bibliotheca cardiologica, Fasc. 10, 1-52.

Sharpe, G. L., and Larsson, K. S. (1975). Studies on closure of the ductus arteriosus. X. In vivo effect of prostaglandin. Prostaglandins, 9, 703-719.

Sharpe, G. L., Larsson, K. S., and Thalme, B. (1975). Studies on closure of the ductus arteriosus. XII. In utero effect of indomethacin and sodium salicylate in rats and rabbits. Prostaglandins, 9, 585-596.

Wielinga, G. (1959). De relatie tussen coarctatio aortae en ligamentum arteriosum. Thesis, Leiden.

Requests for reprints to: Dr. A. C. Gittenberger-de Groot, Department of Anatomy and Embryology, University of Leiden, Wassenaarseweg 62, Leiden, The Netherlands. 